\title{
On the origin of the maternal age effect in trisomy 21 Down syndrome: the Oocyte Mosaicism Selection model
}

\author{
Maj A Hultén ${ }^{1}$, Suketu Patel ${ }^{2}$, Jon Jonasson ${ }^{3}$ and Erik Iwarsson ${ }^{4}$ \\ ${ }^{1}$ Warwick Medical School and ${ }^{2}$ Department of Biological Sciences, University of Warwick, Coventry CV4 7AL, UK, \\ ${ }^{3}$ Clinical Genetics, LMC, University Hospital, S-581 85 Linköping, Sweden and ${ }^{4}$ Clinical Genetics Unit, Department \\ of Molecular Medicine and Surgery, Karolinska Institutet, Karolinska University Hospital, S-171 76 Stockholm, \\ Sweden
}

Correspondence should be addressed to M A Hultén; Email: maj.hulten@warwick.ac.uk

\begin{abstract}
We have recently documented that trisomy 21 mosaicism is common in human foetal ovaries. On the basis of this observation we propose that the maternal age effect in Down syndrome (DS) is caused by the differential behaviour of trisomy 21 in relation to disomy 21 oocytes during development from foetal life until ovulation in adulthood. In particular, we suggest that trisomy 21 oocytes, lagging behind those that are disomic, may escape the timed pruning of the seven million in foetal life to the $300-400$ finally selected for ovulation. The net effect of this preferential elimination will be an accumulation of trisomy 21 oocytes in the ovarian reserve of older women. We here highlight the implications of this Oocyte Mosaicism Selection (OMS) model with respect to the prevalent view that the maternal age effect is complex, dependent on many different biological and environmental factors. We examine conclusions drawn from recent largescale studies in families, tracing DNA markers along the length of chromosome $21 \mathrm{q}$ between parents and DS children, in comparison to the OMS model. We conclude that these family linkage data are equally compatible with the maternal age effect originating from the accumulation of trisomy 21 oocytes with advancing maternal age. One relatively straightforward way to get to grips with what is actually going on in this regard would be to compare incidence of trisomy 21 oocytes (and their pairing configurations) in foetal ovaries with that in oocytes at the meiosis I stage from adult women.
\end{abstract}

Reproduction (2010) 139 1-9

\section{Introduction}

Down syndrome 50 years on: what do we know about the origin?

It is now more than 75 years since the maternal age effect in Down syndrome (DS) was first discovered (Penrose 1933, 1934) and 50 years since the genetic background in DS involving extra chromosome 21 material was identified (Book et al. 1959, Ford et al. 1959, Jacobs et al. 1959, Lejeune et al. 1959, Penrose et al. 1960, Polani et al. 1960). In the interim it has become abundantly clear that the origin of the most common type of DS associated with a free extra chromosome 21 (T21) differs from the more rare types that are dependent on extra chromosome 21 material caused by a structural chromosome rearrangement. In particular, it is exclusively this common type that is associated with an increase dependent on maternal age, a rise which is especially dramatic at later reproductive ages from around 35 years and onwards (Fig. 1).

\section{What is the reason for the T21 maternal age effect?}

Numerous hypotheses have over the years been put forward to explain the T21 maternal age effect (Table 1). Most authors assume that the main problem concerns meiotic segregation errors of a normal disomic oocyte, as reiterated by for example Hunt \& Hassold (2008), Jones (2008), Mailhes (2008), Martin (2008), Oliver et al. (2008), Vogt et al. (2008), Allen et al. (2009), Coppedè (2009), Driscoll \& Gross (2009), Garcia-Cruz et al. (2009) and Ghosh et al. (2009). We have recently performed a study (Hultén et al. 2008) relevant to the possibility that the maternal age effect is instead due to the accumulation of pre-existing T21 cells in ovaries of human females during their development from foetal life to adulthood, a hypothesis akin to the oocyte selection model by Vig (1984), Zheng \& Byers (1992), Sensi \& Ricci (1993), Zheng \& Byers (1996a, 1996b), Zheng et al. (2000) and Zheng (2004). We found that in fact all eight normal foetuses analysed in this respect were T21 ovarian mosaics (average $0.54 \%$, range $0.20-0.88$; 


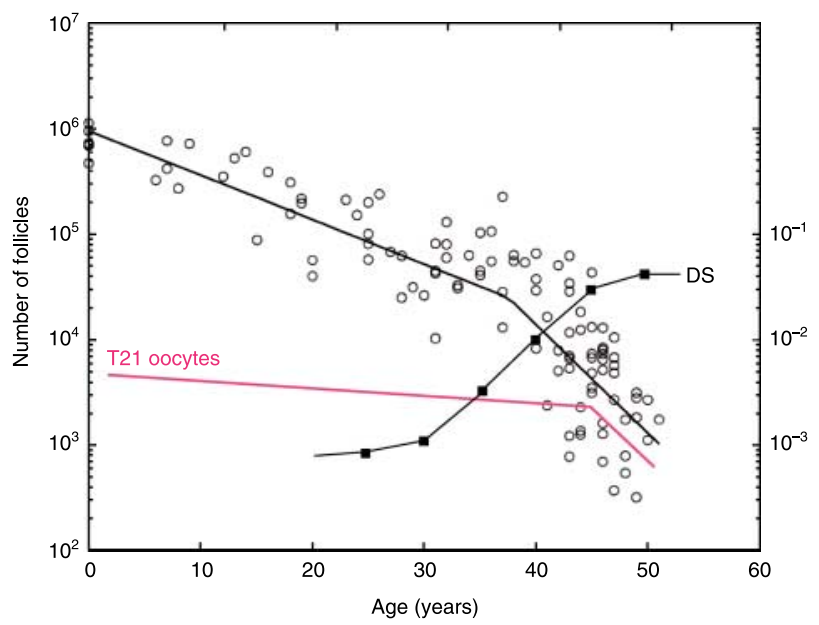

Figure 1 Increased proportion of T21 oocytes in the ageing ovary. The OMS hypothesis proposes that the T21 oocytes lag behind during development, resulting in higher proportions of the total oocyte pool over time. The figure illustrates the predicted number of T21 oocytes from birth until menopause (pink line) in comparison to the total (black circles) based on follicle counts (left hand $Y$ axis) by Faddy (2000). The observed incidence (right hand Yaxis) of T21 DS births (black squares) is represented by the data of Morris et al. (2002). The offset of the (pink) line showing the predicted number of T21 oocytes is based on the $0.54 \%$ mosaicism observed by Hultén et al. (2008). The slope is an approximation generating the expected DS birth rates with increasing maternal age.

S.D. 0.23 ), this foetal ovarian T21 mosaicism originating by pre-meiotic mitotic chromosome 21 segregation errors. Secondly, it is well known from investigation of meiotic behaviour in T21 foetuses that T21 oocytes, forming a bivalent plus a univalent or a trivalent (Fig. 2) may be retarded in their maturation in comparison to oocytes from foetuses with normal karyotypes (Jagiello et al. 1987, Cheng et al. 1998, Barlow et al. 2002). There is thus a distinct possibility that any T21 oocytes present in the normal ovary may accumulate by escaping apoptotic elimination during the drastic reduction from seven million in foetal life to the 300-400 selected for ovulation in adulthood (Fig. 1). The mechanism(s) underlying this developmental retardation is not known and requires further investigation, e.g. along the same lines as has recently been performed with respect to the premature aging in trisomy 21 DS children (Cairney et al. 2009).

\section{Oocyte development takes decades to complete}

It is in this context essential to remember the complexity in oocyte development and meiotic cell divisions, where the crucial crossover process and chiasma formation takes place during foetal development but the oocyte is not undergoing the final cell division until fertilisation in adulthood (see e.g. reviews in Hultén et al. (2005, 2009)). The precursor cells, the primordial germ cells, are differentiated among the endodermal cells of the yolk sac already at around 4 weeks of foetal life. They then migrate to the gonadal ridge, where multiple pre-meiotic oogonial mitotic cell divisions lead to a peak of approximately seven million at 20 weeks gestation.

The meiotic prophase is initiated at around 9 weeks gestation and progresses in a semi-synchronous fashion until a few weeks after birth (Bendsen et al. 2006). At this time, further development is again arrested for several decades until maturation, following the FSH surge from puberty onwards. The first meiotic metaphase I (MI) to anaphase I (AI) division, normally halving the somatic chromosome number from 46 to 23 takes place just before ovulation followed by progression to metaphase II (MII). Oocytes again arrest at this stage with the second meiotic division at anaphase II (AII) not being completed until after fertilisation.

Quite remarkably, therefore, deviations in normal chromosome segregational behaviour from the very earliest mitotic cells divisions of the zygote until the completion of the second meiotic division taking place 15-50 years later following fertilisation may be of importance for the origin of T21 DS conceptions.

\section{Aneuploidy mosaicism is common in human embryos}

One particular aspect of this notion concerns recent information obtained by chromosome analysis of embryos at the 8-cell stage, indicating that chromosome malsegregation of one or a few chromosomes is common, leading to embryonic mosaicism including a cell line with an aberrant chromosome number (see e.g. Hultén et al. 2009, Vanneste et al. 2009). The relevance of this observation in relation to the origin of ovarian T21 mosaicism that we have documented previously (Hultén et al. 2008) is, however, not yet known. First of all, the number of embryos so far investigated in this respect at the 8-9-cell stage is still small, and the involvement of T21 mosaicism per se has not been clarified. Secondly, in the absence of knowledge as regards the origin of any such T21 embryonic mosaicism, the relevance of the indication by Katz-Jaffe et al. (2004) that it is only those that are 'meiotic' that survive until the time of amniocentesis (around 16 weeks gestational age) remains unknown. Thirdly, we do not know what the relation might be between any T21 mosaicism in somatic and germ line cells of the embryo. Fourth, bearing in mind the tiny founding germ cell population (2-3 cells) suggested by Zheng et al. (2005) it seems highly unlikely that earlier malsegregation underlies the foetal ovarian T21 mosaicism at an average of $0.54 \%$ that we detected in the eight cases at gestational age 14-22 weeks. Tentatively, we propose that this has been caused by oogonial malsegregation at around 5 -week gestational age, i.e. when the migrating germ cells have reached their final destination in the mesenchyme of the urogenital ridge (Bendsen et al. 2006, Pereda et al. 2006). 
Table 1 Examples of hypotheses aimed at explaining the maternal age effect in T21 Down syndrome.

\begin{tabular}{|c|c|}
\hline Hypothesis & References \\
\hline $\begin{array}{l}\text { Altered meiotic recombination laid down in foetal oocytes/mechanical } \\
\text { instability at } \mathrm{MI}-\mathrm{Al} \text { transition/AI chromosome malsegregation }\end{array}$ & $\begin{array}{l}\text { Penrose (1954), Henderson \& Edwards (1968), Warren et al. (1987), } \\
\text { Sherman et al. (1991), Lamb et al. (2005), Hunt \& Hassold (2008), } \\
\text { Mailhes (2008), Oliver et al. (2008) and Allen et al. (2009) }\end{array}$ \\
\hline Variation in centromeric alphoid DNA & Maratou et al. (2000) \\
\hline Impaired meiotic sister chromatid cohesion at $\mathrm{Ml}-\mathrm{Al}$ & $\begin{array}{l}\text { Watanabe \& Nurse (1999), Schon et al. (2000), de Bruin et al. } \\
\text { (2004), Eichenlaub-Ritter et al. (2004), Hodges et al. (2005), } \\
\text { Steuerwald et al. (2005), Mailhes (2008), Subramanian \& Bickel } \\
\text { (2008) and Vogt et al. (2008) }\end{array}$ \\
\hline $\begin{array}{l}\text { Impaired chromatin condensation/mechanical instability at MI - Al } \\
\text { transition }\end{array}$ & Hultén (1990) \\
\hline Impaired spindles at AI and AII & $\begin{array}{l}\text { Hawley et al. (1994), Battaglia et al. (1996), Van Blerkom et al. } \\
\text { (1997), LeMaire-Adkins et al. (1997), Eichenlaub-Ritter (1998), } \\
\text { Volarcik et al. (1998), Steuerwald et al. (2001), Homer et al. } \\
\text { (2005), Ma et al. (2005), Mailhes (2008) and Vogt et al. (2008) }\end{array}$ \\
\hline $\begin{array}{l}\text { Accumulation of toxic effects/environmental insults/virus/mitochon- } \\
\text { drial mutations/cytoplasmic agents/energy deficit/protein deficit in } \\
\text { oocytes during foetal and postnatal development }\end{array}$ & $\begin{array}{l}\text { Penrose (1954), Stoller \& Collmann (1965), Evans (1967), Beermann } \\
\text { \& Hansmann (1986), Van Blerkom et al. (1998), Jansen \& de Boer } \\
\text { (1998), Schon et al. (2000) and Sherman et al. (2007) }\end{array}$ \\
\hline Foetal ovarian T21 mosaicism, the OMS model & $\begin{array}{l}\text { Vig (1984), Zheng \& Byers (1992), Sensi \& Ricci (1993), Zheng \& } \\
\text { Byers (1996a, 1996b) and Hultén et al. (2008) }\end{array}$ \\
\hline Grandmaternal age effect implying foetal ovarian T21 mosaicism & $\begin{array}{l}\text { Penrose (1954), Greenberg (1963), Stoller \& Collmann (1969), } \\
\text { Richards (1970), Papp et al. (1977), Aagesen et al. (1984) and } \\
\text { Malini \& Ramachandra (2006) }\end{array}$ \\
\hline Limited oocyte pool/reduced ovarian reserve/premature menopause & $\begin{array}{l}\text { Eichenlaub-Ritter \& Boll (1989), Warburton (1989), Gaulden } \\
\text { (1992), Kline \& Levin (1992), Freeman et al. (2000), Kline et al. } \\
\text { (2000), van Montfrans et al. (2002), Kline et al. (2004) and } \\
\text { Warburton (2005) }\end{array}$ \\
\hline $\begin{array}{l}\text { Defective oocytes through hormonal imbalance, e.g. raised FSH/E2, } \\
\text { serum AMH changes }\end{array}$ & $\begin{array}{l}\text { van Montfrans et al. (1999), Nasseri et al. (1999), Seifer et al. (2007) } \\
\text { and Sherman et al. (2007) }\end{array}$ \\
\hline $\begin{array}{l}\text { Decreased time to ovulation/delayed fertilisation due to reduced sexual } \\
\text { activity }\end{array}$ & German (1968) and Klein et al. (1996) \\
\hline Increased miscarriage rate/relaxed selection against T21 conceptions & $\begin{array}{l}\text { Erickson (1978), Aymé \& Lippman-Hand (1982) and Neuhäuser \& } \\
\quad \text { Krackow (2007) }\end{array}$ \\
\hline
\end{tabular}

\section{The Oocyte Mosaicism Selection model}

As regards the origin of T21 emphasis has previously been placed on maternal T21 oocyte selection taking place postnatally during oocyte development from puberty until menopause (Vig 1984, Zheng \& Byers 1992, Sensi \& Ricci 1993, Zheng \& Byers 1996a, $1996 b)$ and a mathematical model to this effect has been produced by Zheng et al. (2000). The implication of our version of this model, which we have here termed OMS for Oocyte Mosaicism Selection, is twofold. First, we hypothesise that the majority of T21 conceptions may originate by obligate nondisjunction of a maternal T21 oocyte at the first meiotic division (T21-ND), a type of non-disjunction called secondary non-disjunction in classical genetics (Cooper 1948). This proposal stands in contrast to the current dogma implying that the most common reason for T21 DS conceptions is non-disjunction of the two chromosomes 21 in a normal disomy 21 maternal oocyte (D21-ND). The differentiation between these two alternatives is illustrated in Figs 3 and 4. Secondly, and most importantly we explore the view that the maternal age effect in trisomy 21 DS is most readily explained by accumulation of pre-existing T21 oocytes during maternal oogenesis.

\section{Data analysis and discussion}

The OMS model changes the way we may interpret observations using family linkage analysis, performed with a view to obtaining information on the mode of chromosome 21 parental chromosome segregation errors. We here exemplify this notion by a revised analytical approach to the data presented in recent largescale family linkage studies, where the authors emphasise the likelihood of a complex association between advanced maternal age and non-disjunction of chromosome 21 during oogenesis (Lamb et al. 2005, Oliver et al. 2008, Allen et al. 2009).

This type of study first of all demonstrates that, in the outstanding majority of DS families, the extra chromosome 21 in the DS child is of maternal origin. It is further concluded that maternal chromosome 21 non-disjunction, taking place just before ovulation (maternal meiosis I non-disjunction, MMI ND), is three times as common as chromosome 21 non-disjunction, taking place after fertilisation (maternal meiosis II non-disjunction, MMII ND). Thirdly, the data are taken to indicate that there are three types of aberrant 'vulnerable' maternal recombination patterns, i.e. 1) lack of a maternal crossover on $21 \mathrm{q}$, 2) a more distal than normal single maternal crossover on $21 \mathrm{q}$, and 3) a more proximal than normal maternal 

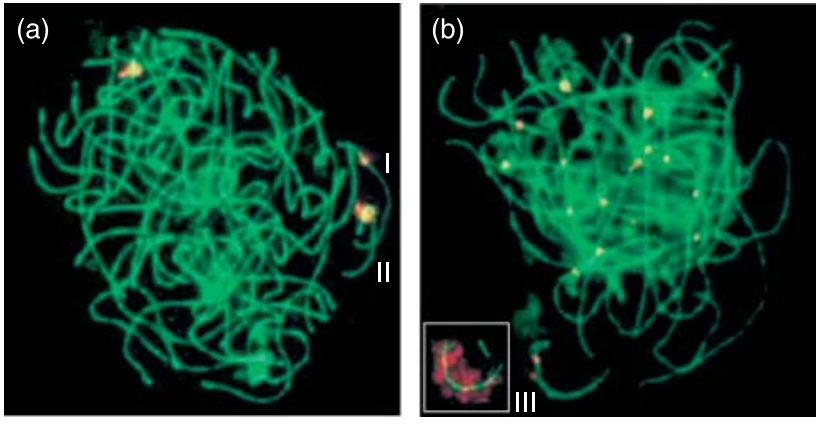

Figure 2 Trisomy 21 oocytes at the full pairing (pachytene) stage, following immunofluorescence staining for identification of the Synaptonemal Complexes (the proteinaceous structure holding the homologues together). (a) Foetal T21 oocyte containing a bivalent 21 (II) and a univalent 21 (I) identified by FISH, using a 13/21 centromeric probe (I); the univalent 21 lies close to and is much longer than the bivalent 21. (b) Foetal T21 oocyte containing a trivalent 21 (III) that shows lengthy triple synapsis. The centromeres identified by the CREST antibody (in yellow and red) are asymmetrically located, suggesting non-homologous association within the region of triple synapsis. Distally, one axis protrudes from the configuration. The insert shows the T21 highlighted by FISH (in yellow) using a whole chromosome 21 paint. Reproduced from Barlow et al. (2002) with permission.

single crossover on $21 \mathrm{q}$. Fourthly, it is only the more proximal than normal maternal single crossover on $21 \mathrm{q}$ that is maternal age dependent (Fig. 5).

\section{Maternal age dependent T21-ND cannot be distinguished by family linkage analysis}

In the most recent study, Allen et al. (2009) compared polymorphic DNA markers along the length of the long arm of chromosome 21 in a large cohort of parents and live born DS children, selected from more than 1000 DS families and controls respectively. At least one $21 \mathrm{q}$ marker had to be informative when DNA from both parents could be analysed and eight markers when only maternal DNA was available. In a total population of 930 such cases they classified those where parental heterozygosity had been retained as originating from MMI ND, implying failure of the two homologs 21 in a normal disomy 21 oocyte to separate properly (Fig. 3b and c). On the alternative OMS model we note that the very same result is a likely outcome of obligate MMI ND in a T21 oocyte, containing a univalent and a bivalent (Fig. 2a), i.e. when the chromatids of the univalent undergo precocious separation at Al (Fig. 4a). We conclude that 1) any maternal age effect caused by accumulation of pre-existing T21 oocytes under the OMS model will not have been detected by the approach used by Allen et al. (2009), and 2) their data are not inconsistent with a maternal age effect caused by accumulation of pre-existing T21 oocytes with advancing maternal age.

\section{The maternal age dependent 21q proximal recombination is the typical in $\mathrm{T} 21$ trivalents}

In the study by Allen et al. (2009), the MMI ND type of segregation error, presumed to involve the two chromosomes 21 in a normal disomy 21 oocyte (D21-ND; Fig. 3b and c) was recorded as the most common, occurring in $76 \%$ of cases (730/960). A subset of these 730 cases has previously been investigated by Lamb et al. (2005) and Oliver et al. (2008). In these earlier investigations, the majority of cases interpreted to be due to MMI ND were found to either lack a parental chromosome 21 crossover or showing a crossover near the end of $21 \mathrm{q}$. Both these types of $\mathrm{MMI}$ ND were considered to be equally common among the different age groups, these patterns thus interpreted to influence the risk for ND irrespective of maternal age. Under the OMS model, we again note that these results are those expected in respectively a T21 oocyte forming a bivalent plus a univalent (Fig. 4a) and a T21 oocyte forming a trivalent (Fig. 4b in Hultén et al. (2008)). (a)

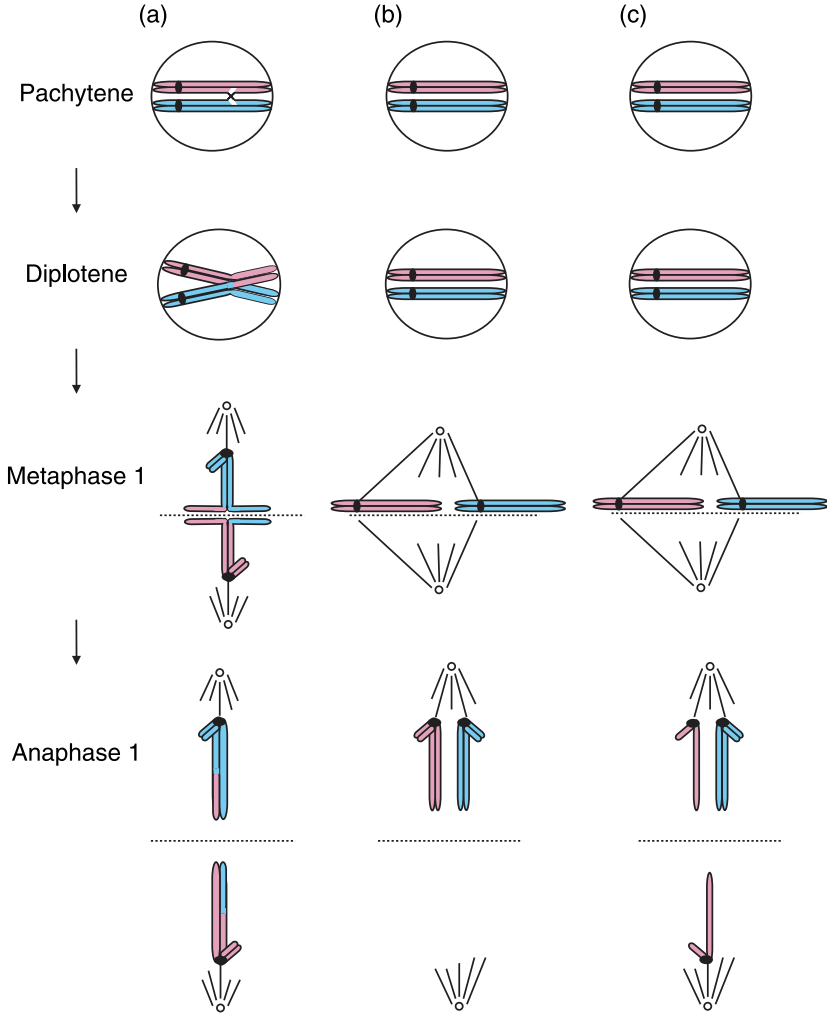

Figure 3 Cartoon illustrating the different types of meiosis I segregation that may take place in a normal disomy 21 oocyte. (a) Normal chromosome pairing and crossing-over, attachment of the movement centres (kinetochores) at metaphase I and separation at anaphase I. (b) Lack of crossing-over and chiasma formation may lead to primary non-disjunction at anaphase I. (c) Lack of a chiasma can also lead to the same type of segregation at anaphase I as during mitosis (precocious meiotic disjunction). 
(a)
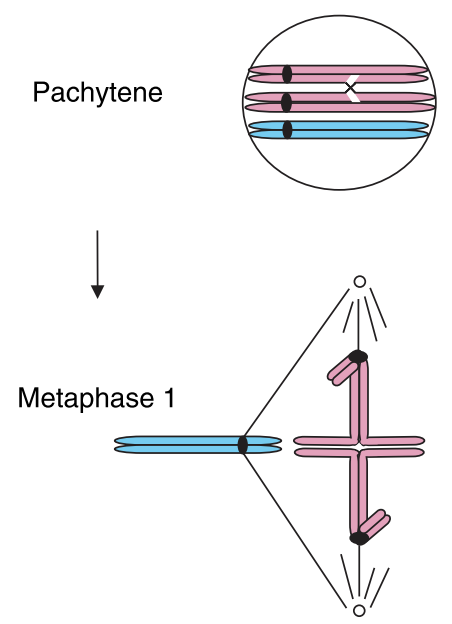

$\downarrow$
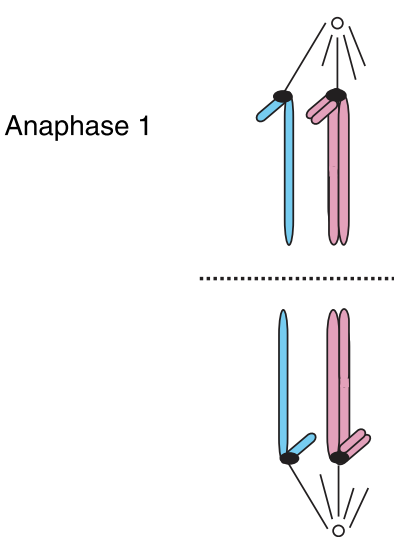

Figure 4 Cartoon illustrating the different types of secondary nondisjunction that may take place in a T21 oocyte. (a) Formation of a bivalent with a chiasma formed in the middle of the long arm plus a univalent, where the univalent is undergoing precocious disjunction leading to a chromosome 21 plus a chromatid in each of the daughter cells. (b) Formation of a trivalent with chiasmata in aberrant positions, i.e. in this example proximally within the long arm. Obligate secondary non-disjunction at anaphase I will lead to two chromosomes 21 travelling into one of the daughter cells and one chromosome 21 into the other.

In contrast, cases interpreted by Lamb et al. (2005) and Oliver et al. (2008) to be due to MMII ND on the basis of reduction of parental heterozygosity (including nearcentromeric markers) with a near-centromeric crossover, were different in as much as they were considered to be maternal age dependent. On the basis of the OMS model, we suggest that these cases could equally well be the result of obligate non-disjunction (T21-ND), i.e. in an oocyte carrying a trivalent 21 (Figs $2 \mathrm{~b}$ and $4 \mathrm{~b}$ ).

We conclude 1) that these earlier family linkage data are compatible with the OMS model explaining the maternal age effect in T21 DS. We further suggest that 2) the net result as regards those oocytes finally selected for ovulation is likely to be dependent on three main factors, i.e. i) the incidence of T21 oocytes in the original foetal pool, ii) the specific pairing configurations (bivalent plus univalent or trivalent) and iii) their respective fate due to differential oocyte selection during oogenesis (Fig. 1).

\section{Additional complexity in interpreting results and further studies}

In this context, it is essential to recognise the complexity in extrapolation of data obtained by family linkage to 1) original patterns of grandparental recombination taking place during maternal foetal development (Hultén \& Tease 2003a, 2003b) and 2) segregation of grandparental chromosomes during maternal Al taking place just before ovulation. It is also important to recognise that the variant synapsis in any T21 oocyte (Jagiello et al. 1987, Cheng et al. 1998, Barlow et al. 2002) may lead to a number of different patterns of recombination, where those illustrated here (Fig. 4) and in Hultén et al. (2008) (Fig. 4) only represent some possibilities.

Further information on patterns of $21 \mathrm{q}$ recombination would be valuable, using analysis of MLH1 recombination foci along the length of the meiosis-specific chromosome pairing structure, the synaptonemal complex at the pachytene stage (Baker et al. 1996, Barlow \& Hultén 1998, Tease et al. 2002, 2006, Tease \& Hultén 2004, Lenzi et al. 2005, Robles et al. 2007). The normal positioning of a single MLH1 recombination focus in the middle of $21 \mathrm{q}$ is illustrated in Fig. 6. Our own studies using this approach in T21 foetuses have so far been hampered by the maturation delay of T21 oocytes in comparison to foetuses with normal karyotypes. Thus, analysis of foetal T21 ovaries, where termination of pregnancy had been performed at around 16 weeks gestation, has not allowed the relevant information on $\mathrm{MLH} 1$ recombination foci to be obtained, as only oocytes at the earlier leptotene and zygotene stages have been identified (M Hultén, S Patel \& E Iwarsson 2008, unpublished observations).

Until detailed information on the recombination along $21 \mathrm{q}$ in a number of T21 foetuses and a large population of oocytes per case becomes available, it is difficult to state what the reason might be for the reduced rate of MMl- type D21 non-disjunction detected by Allen et al. (a)

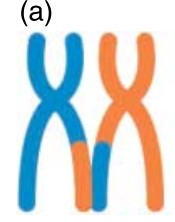

(b)

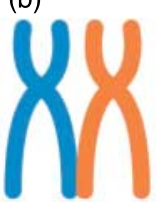

(c)

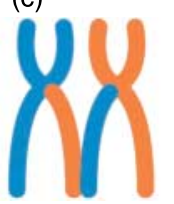

(d)

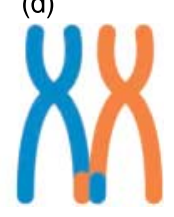

Figure 5 Cartoon illustrating normal positioning, absence and aberrant crossover positions on 21q; revised from Fig. 1 in Hassold \& Hunt (2007). (a) Optimal location of a single crossover, in the middle of the long arm. (b) Absence of crossover. (c) Single crossover located too near to the centromere. (d) Single crossover located too far from the centromere. 


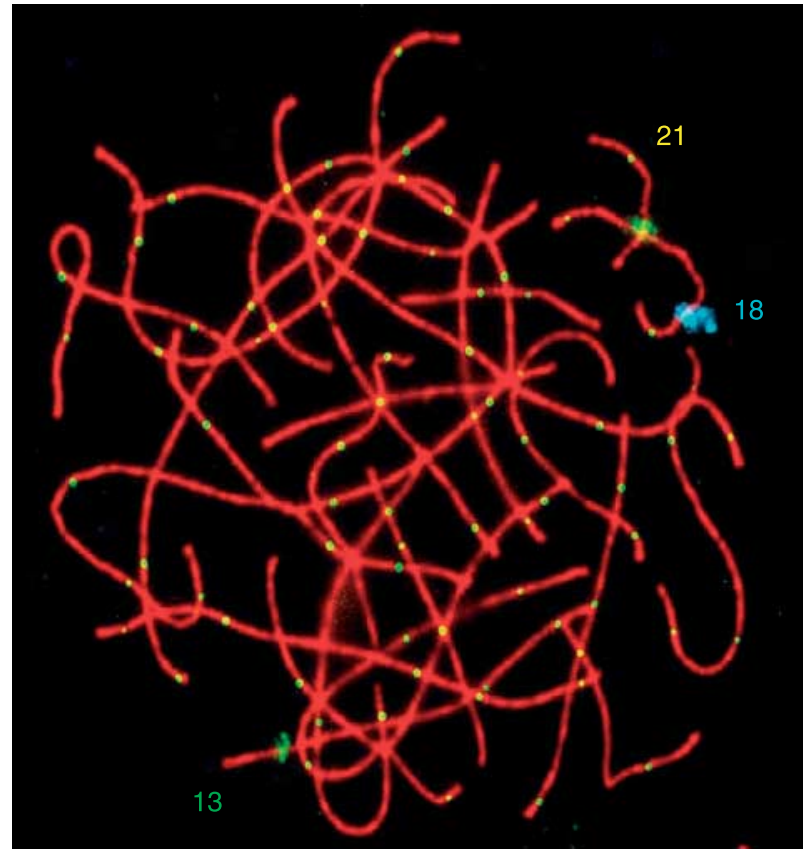

Figure 6 Normal 21 oocyte at the full pairing (pachytene) stage following dual immunofluorescence staining for identification of the synaptonemal complexes and the MLH1 recombination foci (in yellow) and subsequent fluorescence in situ hybridisation (FISH) with probes, highlighting the centromeres of chromosomes 21 and 13 (in green) and chromosome 18 (in blue). Revised from Fig. 1 in Tease et al. (2002).

(2009) in mothers within the youngest and oldest age groups. Tentatively, we suggest that under the OMS model this may be due to the combination of differences in 1) degree of foetal T21 ovarian mosaicism, where young mothers may more often be high-grade T21 ovarian mosaics, and 2) the behaviour of the different types of T21 synaptic configurations during development, where oocytes forming a trivalent 21 may show some specificity in apoptotic selection/developmental delay in comparison to those carrying a bivalent plus a univalent.

\section{The OMS model may apply to other constitutional aneuploidies}

Finally, although we have here focused attention on the maternal age effect in trisomy 21 DS, this condition being the most common genetic disorder in the human population, it is important to note that the same model may apply to other common constitutional aneuplodies, such as trisomy 18 Edwards and trisomy 13 Patau syndrome as well as to some of the sex chromosome aberrations. Thus, we have previously suggested that under the OMS model trisomy 21 foetal mosaicism might represent only the tip of the iceberg (Hultén et al. 2008). Further studies will obviously be required to sort out the potential role of gonadal mosaicism for the origin of constitutional aneuploidy in the human population. It will also be of special interest to find out to what extent foetal testicular T21 mosaicism is underlying the paternal origin of T21 offspring, constituting only around $5-10 \%$ of the total, and where there is by comparison only a very weak age effect (De Souza et al. 2009).

\section{Conclusion}

In conclusion, we suggest that the new information that we have recently reported on as regards the common occurrence of ovarian T21 mosaicism (Hultén et al. 2008), and the support thereby provided for the OMS model underlying the maternal age effect in trisomy 21 DS, imply that the time is now ripe for a paradigm shift. Thus, we propose that the OMS model should be seriously considered as a relevant alternative to other proposals on the origin of the maternal age effect in trisomy 21 DS, including in particular those concluding that this is a highly complex situation, where many different biological and environmental factors may be at play (Mailhes 2008, Martin 2008, Oliver et al. 2008, Vogt et al. 2008, Allen et al. 2009, Coppedè 2009, Driscoll \& Gross 2009, Garcia-Cruz et al. 2009, Ghosh et al. 2009). In contrast, we suggest that, by comparison, the OMS model provides a straightforward explanation. Thus, we propose that 1 ) obligate first meiotic T21-ND may be the prevailing mechanism for T21 conceptions of maternal origin, 2) the maternal age effect is due to accumulation of T21 oocytes with advancing age, and 3 ) this model is compatible with results obtained on maternal segregation and recombination patterns recently recorded by DS family linkage analysis (Lamb et al. 2005, Hunt \& Hassold 2008, Oliver et al. 2008, Allen et al. 2009).

As we have commented on in our previous report (Hultén et al. 2008) one relatively straightforward way to test the OMS model would be to compare the incidence of T21 oocytes in a pool of foetal oocytes in relation to that in oocytes from adult women at different biological ages, obtained from for example oophorectomies and during IVF treatment due to male factor fertility problems. In view of the statement by Allen et al. (2009) that the basis of the maternal age effect in aneuploidy remains one of the most important questions in medical genetics, it is hoped that such a study can be realised in the not too distant future. We would welcome notification from any colleagues who would be interested in taking part in this type of collaborative study.

\section{Declaration of interest}

The authors declare that there is no conflict of interest that could be perceived as prejudicing the impartiality of the research reported. 


\section{Funding}

This work has been supported by grants from the Wellcome Trust (Grant No 061202/ZOOZ), BBSRC (Grant No BB/C003500/1), The Swedish Research Council and Stockholm County Council.

\section{Acknowledgements}

This paper is dedicated to Marthe Gautier and Patricia Jacobs for their pioneering work on Down syndrome.

\section{References}

Aagesen L, Grinsted J \& Mikkelsen M 1984 Advanced grandmaternal age on the mother's side - a risk of giving rise to trisomy 21. Annals of Human Genetics 48 297-301.

Allen EG, Freeman SB, Druschel C, Hobbs CA, O'Leary LA, Romitti PA, Royle MH, Torfs CP \& Sherman SL 2009 Maternal age and risk for trisomy 21 assessed by the origin of chromosome nondisjunction: a report from the Atlanta and National Down Syndrome Projects. Human Genetics 125 41-52.

Aymé S \& Lippman-Hand A 1982 Maternal-age effect in aneuploidy: does altered embryonic selection play a role? American Journal of Human Genetics 34 558-565.

Baker SM, Plug AW, Prolla TA, Bronner CE, Harris AC, Yao X, Christie DM, Monell C, Arnheim N, Bradley A et al. 1996 Involvement of mouse Mlh1 in DNA mismatch repair and meiotic crossing over. Nature Genetics $\mathbf{1 3}$ 336-342.

Barlow AL \& Hultén MA 1998 Crossing over analysis at pachytene in man. European Journal of Human Genetics 6 350-358.

Barlow AL, Tease C \& Hultén MA 2002 Meiotic chromosome pairing in fetal oocytes of trisomy 21 human females. Cytogenetic and Genome Research 96 45-51.

Battaglia DE, Goodwin P, Klein NA \& Soules MR 1996 Influence of maternal age on meiotic spindle assembly in oocytes from naturally cycling women. Human Reproduction 11 2217-2222.

Beermann F \& Hansmann I 1986 Follicular maturation, luteinization and first meiotic division in oocytes after inhibiting mitochondrial function in mice with chloramphenicol. Mutation Research 160 47-54.

Bendsen E, Byskov AG, Andersen CY \& Westergaard LG 2006 Number of germ cells and somatic cells in human fetal ovaries during the first weeks after sex differentiation. Human Reproduction 21 30-35.

Van Blerkom J, Antczak M \& Schrader R 1997 The developmental potential of the human oocyte is related to the dissolved oxygen content of follicular fluid: association with vascular endothelial growth factor levels and perifollicular blood flow characteristics. Human Reproduction 12 1047-1055.

Van Blerkom J, Sinclair J \& Davis P 1998 Mitochondrial transfer between oocytes: potential applications of mitochondrial donation and the issue of heteroplasmy. Human Reproduction 13 2857-2868.

Book JA, Fraccaro M \& Lindsten J 1959 Cytogenetical observations in mongolism. Acta Paediatrica 48 453-468.

de Bruin JP, Dorland M, Spek ER, Posthuma G, van Haaften M, Looman CW \& te Velde ER 2004 Age-related changes in the ultrastructure of the resting follicle pool in human ovaries. Biology of Reproduction $\mathbf{7 0}$ 419-424.

Cairney CJ, Sanguinetti G, Ranghini E, Chantry AD, Nostro MC, Bhattacharyya A, Svendsen CN, Keith WN \& Bellantuono I 2009 A systems biology approach to Down syndrome: identification of Notch/Wnt dysregulation in a model of stem cells aging. Biochimica et Biophysica Acta 1792 353-363.

Cheng EY, Chen YJ, Bonnet G \& Gartler SM 1998 An analysis of meiotic pairing in trisomy 21 oocytes using fluorescent in situ hybridization. Cytogenetics and Cell Genetics 80 48-53.

Cooper KW 1948 A new theory of secondary non-disjunction in female Drosophila melanogaster. PNAS 34 179-187.
Coppedè $\mathbf{F} 2009$ The complex relationship between folate/homocysteine metabolism and risk of Down syndrome. Mutation Research 682 54-70.

Driscoll DA \& Gross S 2009 Clinical practice. Prenatal screening for aneuploidy. New England Journal of Medicine 360 2556-2562.

Eichenlaub-Ritter U 1998 Genetics of oocyte ageing. Maturitas 30 143-169.

Eichenlaub-Ritter U \& Boll I 1989 Age-related non-disjunction, spindle formation and progression through maturation of mammalian oocytes. Progress in Clinical and Biological Research 318 259-269.

Eichenlaub-Ritter U, Vogt E, Yin H \& Gosden R 2004 Spindles, mitochondria and redox potential in ageing oocytes. Reproductive Biomedicine Online 8 45-58.

Erickson JD 1978 Down syndrome, paternal age, maternal age and birth order. Annals of Human Genetics 41 289-298.

Evans HJ 1967 The nucleolus, virus infection, and trisomy in man. Nature 214 361-363.

Faddy MJ 2000 Follicle dynamics during ovarian ageing. Molecular and Cellular Endocrinology 163 43-48.

Ford CE, Jones KW, Miller OJ, Mittwoch U, Penrose LS, Ridler M \& Shapiro A 1959 The chromosomes in a patient showing both mongolism and the Klinefelter syndrome. Lancet 1 709-710.

Freeman SB, Yang Q, Allran K, Taft LF \& Sherman SL 2000 Women with a reduced ovarian complement may have an increased risk for a child with Down syndrome. American Journal of Human Genetics 66 1680-1683.

Garcia-Cruz R, Roig I \& Caldes MG 2009 Maternal origin of the human aneuploidies. Are homolog synapsis and recombination to blame? Notes (learned) from the underbelly. Genome Dynamics 5 128-136.

Gaulden ME 1992 Maternal age effect: the enigma of Down syndrome and other trisomic conditions. Mutation Research 296 69-88.

German J 1968 Mongolism, delayed fertilization and human sexual behaviour. Nature 217 516-518.

Ghosh S, Feingold E \& Dey SK 2009 Etiology of Down syndrome: evidence for consistent association among altered meiotic recombination, nondisjunction, and maternal age across populations. American Journal of Medical Genetics. Part A 149A 1415-1420.

Greenberg RC 1963 Two factors influencing the births of mongols to younger mothers. Medical Officer 109 62-64.

Hassold T \& Hunt P 2007 Rescuing distal crossovers. Nature Genetics 39 1187-1188.

Hawley RS, Frazier JA \& Rasooly R 1994 Separation anxiety: the etiology of nondisjunction in flies and people. Human Molecular Genetics 3 1521-1528.

Henderson SA \& Edwards RG 1968 Chiasma frequency and maternal age in mammals. Nature 218 22-28.

Hodges CA, Revenkova E, Jessberger R, Hassold TJ \& Hunt PA 2005 SMC1beta-deficient female mice provide evidence that cohesins are a missing link in age-related nondisjunction. Nature Genetics 37 $1351-1355$.

Homer HA, McDougall A, Levasseur M, Yallop K, Murdoch AP \& Herbert M 2005 Mad2 prevents aneuploidy and premature proteolysis of cyclin B and securin during meiosis I in mouse oocytes. Genes and Development 19 202-207.

Hultén MA 1990 The origin of aneuploidy: bivalent instability and the maternal age effect in trisomy 21 Down syndrome. American Journal of Medical Genetics 7 160-161.

Hultén MA \& Tease C 2003a Genetic mapping: comparison of direct and indirect approaches. In Nature Encylopedia of the Human Genome, pp 876-881. Ed. DN Cooper. London: Nature Publishing Group.

Hultén MA \& Tease C 2003b Genetic maps: direct meiotic analysis. In Nature Encylopedia of the Human Genome, pp 882-887. Ed. DN Cooper. London: Nature Publishing Group.

Hultén MA, Baker H \& Tankimanova M 2005 Meiosis and meiotic errors. In Encyclopedia of Genetics, Genomics, Proteomics and Bioinformatics (online version), Eds LB Jorde, PFR Little, MJ Dunn \& S Subramaniam. Chichester: John Wiley \& Sons Ltd.

Hultén MA, Patel SD, Tankimanova M, Westgren M, Papadogiannakis N, Jonsson AM \& Iwarsson E 2008 On the origin of trisomy 21 Down syndrome. Molecular Cytogenetics 121.

Hultén MA, Smith E \& Delhanty JDA 2009 Errors in meiotic chromosome behaviour during oogenesis. In Reproductive Endocrinology and Infertility: The Practical Clinic and Laboratory (in press), Ed. DT Carrell. Totowa, NJ: Humana Press. 
Hunt PA \& Hassold TJ 2008 Human female meiosis: what makes a good egg go bad? Trends in Genetics 24 86-93.

Jacobs PA, Baikie AG, Court Brown WM \& Strong JA 1959 The somatic chromosomes in mongolism. Lancet $\mathbf{1} 710$.

Jagiello GM, Fang JS, Nogawa T, Sung WK, Ducayen MB \& Bowne W 1987 Chromosome 21 behavior during fetal oogenesis in Down's syndrome. Obstetrics and Gynecology 70 878-883.

Jansen RP \& de Boer K 1998 The bottleneck: mitochondrial imperatives in oogenesis and ovarian follicular fate. Molecular and Cellular Endocrinology 145 81-88.

Jones KT 2008 Meiosis in oocytes: predisposition to aneuploidy and its increased incidence with age. Human Reproduction Update 14 143-158.

Katz-Jaffe MG, Trounson AO \& Cram DS 2004 Mitotic errors in chromosome 21 of human preimplantation embryos are associated with non-viability. Molecular Human Reproduction 10 143-147.

Klein NA, Battaglia DE, Fujimoto VY, Davis GS, Bremner WJ \& Soules MR 1996 Reproductive aging: accelerated ovarian follicular development associated with a monotropic follicle-stimulating hormone rise in normal older women. Journal of Clinical Endocrinology and Metabolism 81 1038-1045.

Kline J \& Levin B 1992 Trisomy and age at menopause: predicted associations given a link with rate of oocyte atresia. Paediatric and Perinatal Epidemiology 6 225-239.

Kline J, Kinney A, Levin B \& Warburton D 2000 Trisomic pregnancy and earlier age at menopause. American Journal of Human Genetics $\mathbf{6 7}$ 395-404.

Kline J, Kinney A, Reuss ML, Kelly A, Levin B, Ferin M \& Warburton D 2004 Trisomic pregnancy and the oocyte pool. Human Reproduction 19 1633-1643.

Lamb NE, Sherman SL \& Hassold TJ 2005 Effect of meiotic recombination on the production of aneuploid gametes in humans. Cytogenetic and Genome Research 111 250-255.

Lejeune J, Turpin R \& Gautier M 1959 Mongolism; a chromosomal disease (trisomy). Bulletin de l'Acadèmie Nationale de Mèdecine $\mathbf{1 4 3}$ 256-265.

LeMaire-Adkins R, Radke K \& Hunt PA 1997 Lack of checkpoint control at the metaphase/anaphase transition: a mechanism of meiotic nondisjunction in mammalian females. Journal of Cell Biology 139 1611-1619.

Lenzi ML, Smith J, Snowden T, Kim M, Fishel R, Poulos BK \& Cohen PE 2005 Extreme heterogeneity in the molecular events leading to the establishment of chiasmata during meiosis I in human oocytes. American Journal of Human Genetics 76 112-127.

Ma W, Zhang D, Hou Y, Li YH, Sun QY, Sun XF \& Wang WH 2005 Reduced expression of MAD2, BCL2, and MAP kinase activity in pig oocytes after in vitro aging are associated with defects in sister chromatid segregation during meiosis II and embryo fragmentation after activation. Biology of Reproduction 72 373-383.

Mailhes JB 2008 Faulty spindle checkpoint and cohesion protein activities predispose oocytes to premature chromosome separation and aneuploidy. Environmental and Molecular Mutagenesis 49 642-658.

Malini SS \& Ramachandra NB 2006 Influence of advanced age of maternal grandmothers on Down syndrome. BMC Medical Genetics 74.

Maratou K, Siddique Y, Kessling AM \& Davies GE 2000 Variation in alphoid DNA size and trisomy 21: a possible cause of nondisjunction. Human Genetics 106 525-530.

Martin RH 2008 Meiotic errors in human oogenesis and spermatogenesis. Reproductive Biomedicine Online 16 523-531.

van Montfrans JM, Dorland M, Oosterhuis GJ, van Vugt JM, RekersMombarg LT \& Lambalk CB 1999 Increased concentrations of folliclestimulating hormone in mothers of children with Down's syndrome. Lancet 353 1853-1854.

van Montfrans JM, van Hooff MH, Martens F \& Lambalk CB 2002 Basal $\mathrm{FSH}$, estradiol and inhibin B concentrations in women with a previous Down's syndrome affected pregnancy. Human Reproduction 17 44-47.

Morris JK, Mutton DE \& Alberman E 2002 Revised estimates of the maternal age specific live birth prevalence of Down's syndrome. Journal of Medical Screening 9 2-6.

Nasseri A, Mukherjee T, Grifo JA, Noyes N, Krey L \& Copperman AB 1999 Elevated day 3 serum follicle stimulating hormone and/or estradiol may predict fetal aneuploidy. Fertility and Sterility 71 715-718.
Neuhäuser M \& Krackow S 2007 Adaptive-filtering of trisomy 21: risk of Down syndrome depends on family size and age of previous child. Naturwissenschaften 94 117-121.

Oliver TR, Feingold E, Yu K, Cheung V, Tinker S, Yadav-Shah M, Masse N \& Sherman SL $2008 \mathrm{New}$ insights into human nondisjunction of chromosome 21 in oocytes. PLoS Genetics 4 e1000033.

Papp Z, Varadi E \& Szabo Z 1977 Grandmaternal age at birth of parents of children with trisomy 21. Human Genetics 39 221-224.

Penrose LS 1933 The relative effect of paternal and maternal age in mongolism. Journal of Genetics 27 219-224.

Penrose LS 1934 The relative aetiological importance of birth order and maternal age in mongolism. Proceedings of the Royal Society (Biology) 115 431-450.

Penrose LS 1954 Mongolian idiocy (mongolism) and maternal age. Annals of the New York Academy of Sciences 57 494-502.

Penrose LS, Ellis JR \& Delhanty JD 1960 Chromosomal translocations in mongolism and in normal relatives. Lancet 2 409-410.

Pereda J, Zorn T \& Soto-Suazo M 2006 Migration of human and mouse primordial germ cells and colonization of the developing ovary: an ultrastructural and cytochemical study. Microscopic Research and Technique 69 386-395.

Polani PE, Briggs JH, Ford CE, Clarke CM \& Berg JM 1960 A Mongol girl with 46 chromosomes. Lancet 1 721-724.

Richards BW 1970 Observations on mosaic parents of mongol propositi. Journal of Mental Deficiency Research 14 342-346.

Robles P, Roig I, Garcia R, Ortega A, Egozcue J, Cabero LL \& Garcia M 2007 Pairing and synapsis in oocytes from female fetuses with euploid and aneuploid chromosome complements. Reproduction 133 899-907.

Schon EA, Kim SH, Ferreira JC, Magalhaes P, Grace M, Warburton D \& Gross SJ 2000 Chromosomal non-disjunction in human oocytes: is there a mitochondrial connection? Human Reproduction 15 160-172.

Seifer DB, MacLaughlin DT \& Cuckle HS 2007 Serum mullerian-inhibiting substance in Down's syndrome pregnancies. Human Reproduction 22 1017-1020.

Sensi A \& Ricci N 1993 Mitotic errors in trisomy 21. Nature Genetics 5215.

Sherman SL, Takaesu N, Freeman SB, Grantham M, Phillips C, Blackston RD, Jacobs PA, Cockwell AE, Freeman V, Uchida I et al. 1991 Trisomy 21: association between reduced recombination and nondisjunction. American Journal of Human Genetics 49 608-620.

Sherman SL, Allen EG, Bean LH \& Freeman SB 2007 Epidemiology of Down syndrome. Mental Retardation and Developmental Disabilities Research Reviews 13 221-227.

De Souza E, Alberman E \& Morris JK 2009 Down syndrome and paternal age, a new analysis of case-control data collected in the 1960s. American Journal of Medical Genetics. Part A 149A 1205-1208.

Steuerwald N, Cohen J, Herrera RJ, Sandalinas M \& Brenner CA 2001 Association between spindle assembly checkpoint expression and maternal age in human oocytes. Molecular Human Reproduction 7 49-55.

Steuerwald NM, Steuerwald MD \& Mailhes JB 2005 Post-ovulatory aging of mouse oocytes leads to decreased MAD2 transcripts and increased frequencies of premature centromere separation and anaphase. Molecular Human Reproduction 11 623-630.

Stoller A \& Collmann RD 1965 Incidence of infective hepatitis followed by Down's syndrome nine months later. Lancet 2 1221-1223.

Stoller A \& Collmann RD 1969 Grandmaternal age at birth of mothers of children with Down's syndrome (ONGOLISM). Journal of Mental Deficiency Research 13 201-205.

Subramanian VV \& Bickel SE 2008 Aging predisposes oocytes to meiotic nondisjunction when the cohesin subunit SMC1 is reduced. PLOS Genetics 4 e1000263.

Tease C \& Hultén MA 2004 Inter-sex variation in synaptonemal complex lengths largely determine the different recombination rates in male and female germ cells. Cytogenetic and Genome Research 107 208-215.

Tease C, Hartshorne GM \& Hultén MA 2002 Patterns of meiotic recombination in human fetal oocytes. American Journal of Human Genetics 70 1469-1479.

Tease C, Hartshorne GM \& Hultén MA 2006 Altered patterns of meiotic recombination in human fetal oocytes with asynapsis and/or synaptonemal complex fragmentation at pachytene. Reproductive Biomedicine Online 13 88-95. 
Vanneste E, Voet T, Le Caignec C, Ampe M, Konings P, Melotte C, Debrock S, Amyere M, Vikkula M, Schuit F et al. 2009 Chromosome instability is common in human cleavage-stage embryos. Nature Medicine 15 577-583.

Vig BK 1984 Sequence of centromere separation another mechanism for the origin of nondisjunction. Human Genetics 66 239-243.

Vogt E, Kirsch-Volders M, Parry J \& Eichenlaub-Ritter U 2008 Spindle formation, chromosome segregation and the spindle checkpoint in mammalian oocytes and susceptibility to meiotic error. Mutation Research 651 14-29.

Volarcik K, Sheean L, Goldfarb J, Woods L, Abdul-Karim FW \& Hunt P 1998 The meiotic competence of in-vitro matured human oocytes is influenced by donor age: evidence that folliculogenesis is compromised in the reproductively aged ovary. Human Reproduction 13 154-160.

Warburton D 1989 The effect of maternal age on the frequency of trisomy: change in meiosis or in utero selection? Progress in Clinical and Biological Research 311 165-181.

Warburton D 2005 Biological aging and the etiology of aneuploidy. Cytogenetic and Genome Research 111 266-272.

Warren AC, Chakravarti A, Wong C, Slaugenhaupt SA, Halloran SL, Watkins PC, Metaxotou C \& Antonarakis SE 1987 Evidence for reduced recombination on the nondisjoined chromosomes 21 in Down syndrome. Science 237 652-654.

Watanabe Y \& Nurse P 1999 Cohesin Rec8 is required for reductional chromosome segregation at meiosis. Nature $\mathbf{4 0 0} 461-464$.
Zheng CJ 2004 Re: "parity and the risk of Down's syndrome". American Journal of Epidemiology $\mathbf{1 6 0}$ 609-610 (author reply 611).

Zheng CJ \& Byers B 1992 Oocyte selection: a new model for the maternal-age dependence of Down syndrome. Human Genetics 90 $1-6$.

Zheng CJ \& Byers B 1996a When does maternal age-dependent trisomy 21 arise relative to meiosis? American Journal of Human Genetics 59 268-269.

Zheng CJ \& Byers B 1996 Implications of the oocyte-selection hypothesis: a response to the interpretation by antonarakis. American Journal of Human Genetics 59 1397-1398.

Zheng CJ, Guo SW \& Byers B 2000 Modeling the maternal-age dependency of reproductive failure and genetic fitness. Evolution \& Development 2 203-207.

Zheng CJ, Luebeck EG, Byers B \& Moolgavkar SH 2005 On the number of founding germ cells in humans. Theoretical Biology \& Medical Modelling 232.

Received 5 March 2009

First decision 1 May 2009

Revised manuscript received 30 August 2009

Accepted 15 September 2009 